\title{
Frente a la crisis neoliberal, las mujeres se organizan: la experiencia de participación comunitaria de las muje- res de sectores populares en la Argentina
}

\section{Facing the neoliberal crisis, women get organized: the experience of community participation of women from the popular sectors in Argentina}

\author{
Corina Echavarría y Gabriela Bard Wigdor \\ Centro de Investigación y Estudios sobre la Cultura y la Sociedad \\ CIECS/CONICET-UNC \\ c.echavarria@conicet.gov.ar
}

\begin{abstract}
SÍNTESIS
El trabajo propone una reflexión situada de las experiencias de participación comunitaria de mujeres, en ocasión de la crisis de la década neoliberal en la Argentina; considerando que el neoliberalismo, además de redefinir en torno del ajuste las funciones del Estado, reconvirtió la historicidad, las luchas de los actores sociales. En este sentido, pretendemos recuperar el carácter bisagra de la crisis para discutir, caracterizar y analizar la participación politica de las mujeres, particularmente, de los sectores populares en actividades comunitarias; tomando como referencia los relatos de mujeres de barrios populares de Rosario que participaron Programa Gender Inclusive Cities (2009-2011).
\end{abstract}

\begin{abstract}
This work puts forward a located reflection over the experiences of women's community participation, during the crisis of the neoliberal decade in Argentina. Considering that neoliberalism reconverted the historicity, the struggles of social actors. In this sense, we intend to highlight the hinge nature of the crisis times when it come to discussing, describing and analyzing the women's political participation, particularly, those from popular sectors in their community activities; referencing the stories of women from working-class neighborhoods of Rosario that took part of Gender Inclusive Cities Program (2009-2011).
\end{abstract}

Palabras claves: Mujeres de sectores populares, Participación Política, Participación comunitaria, Crisis Neoliberal. 
Keywords: Women from Popular Sectors, Political Participation, Community Participation, Neoliberal Crisis.

\section{Introducción}

"Leer la realidad social con

Ojos de mujeres

Sigue siendo una práctica

Poco frecuente"

Anónimo

Las aproximaciones realizadas a los relatos de las diversas experiencias de participación de las mujeres en la Argentina de los últimos años, nos permiten afirmar que no es posible avanzar en su comprensión sin hacer un recorrido que realice una "escucha atenta" e históricamente situada, de lo que esas mujeres piensan a cerca de sus propias vidas (Harding, 1996). Consideramos que el neoliberalismo y su crisis pueden ser entendidos como un punto de inflexión en la participación de las mujeres, sobre todo de aquellas pertenecientes a sectores populares que salieron a la escena pública para hacerle frente a la crisis.

De allí, que en este trabajo realizamos un recorrido histórico por la década de noventa, enfocando no sólo en las particularidades que asumieron las transformaciones estructurales del Estado en Argentina a partir del neoliberalismo, sino también en los relatos de las mujeres y en sus luchas. Nos proponemos acercarnos a la novedad que representa el contexto de la crisis económico-social en la vida de las mujeres; nuevamente, considerando que ningún tipo de opresión patriarcal es independiente de los factores de clase, etnia, religión, etc., consecuentemente, tampoco lo son las relaciones de género que en él se construyen. Tomamos como referencia las entrevistas en profundidad realizadas con mujeres de barrios populares de Rosario (Argentina) ${ }^{1}$, en las cuales intentaron reconstruir sus experiencias de participación comunitaria.

En este esfuerzo de comprensión de las experiencias de las mujeres, tal como sostienen los estudios feministas, asumimos la redefinición y ampliación de nociones tradicionales del significado histórico, en relación a lo que se considera relevante, de modo que abarcar las experiencias personales y subjetivas lo mismo que las actividades públicas y políticas de las mujeres. Asimismo, buscamos poner de 
relieve el postulado que sostiene que las relaciones de género se construyen en un contexto social, político y económico determinado que condiciona las prácticas en su conservación y transformación.

\title{
El discurso Neoliberal... escenario de privatizaciones
}

\author{
"Para el neoliberalismo económico \\ es prioritario formar buenos consumidores \\ antes que buenos ciudadanos. \\ El consumidor es un cliente; \\ el ciudadano es una persona." \\ Antonio Franco
}

Si nos situamos en el contexto de finales de la década del ochenta, los discursos que en América Latina se referían al Estado mencionaban la sobreexpansión de la intervención del Estado y utilizaban expresiones tales como gigantismo, hipertrofia, macrocefalismo. Todo para hacer alusión a lo que se consideraba la ineficiencia de la gestión estatal en el uso de los recursos productivos, su interferencia en la libre elección de los actores privados y su repercusión en la división del trabajo social. Como afirma Borón, se difunde "un discurso ideológico auto-incriminatorio que iguala todo lo que es estatal con la ineficiencia, la corrupción y el desperdicio, mientras que la 'iniciativa privada' aparece sublimada como la esfera de la eficiencia, de la probidad y de austeridad" $(1998,78)$.

La agenda de reforma del Estado establecida por el Banco Mundial y por otros organismos de financiamiento internacional, en el inicio de la década de noventa, restringió la lectura de la crisis a un problema de racionalidad del modelo keynesiano de intervención estatal y desarrolló propuestas basadas en la centralidad del mercado y en la prioridad de la estabilidad monetaria: centralización y aislamiento político del control sobre la política macroeconómica; descentralización y/o privatización de la burocracia encargada de la prestación de servicios sociales; delegación de las funciones reguladoras y de control a agencias independientes (Draibe y Henrique, 1988; Kaufman, 1998; Ivo, 2001; Schmidt, 2001).

El FMI y el Banco Mundial cobraron una importancia insoslayable en el asfixiamiento del Estado y en las decisiones en materia de política social. Esta fue traducida en términos de "costos" y en- 
deudamiento mientras su pago busca garantizarse en el marco de las políticas de transparencia fiscal. En el informe del año 90, el Banco Mundial dio "énfasis especial" a las operaciones de gestión del Sector Público. Basado en la hipótesis de sobrecarga de demandas, consideró que esta "carga pesada" hizo que sugieran ineficiencias en la administración pública, razón por la cual recomendó un reexamen de la función del Estado, re-evaluación de sus prioridades para "recortar aquellos aspectos que resultaban difíciles de manejar y utilizar todos los recursos en forma más eficaz y eficiente" (Banco Mundial, 1990, 77).

Este discurso hegemónico fundamentó la primera ola de reformas en América Latina ${ }^{2}$, orientando el centro de la coordinación social hacia el mercado, a través de la liberalización comercial, las privatizaciones, la desregulación y la descentralización, en el marco del ajuste estructural de las economías en crisis, particularmente de las altamente endeudadas de la región.

Este diagnóstico no solo redefinió lo que seria deseable en términos de intervención estatal, sino que además "reconverte a historicidade dos atores sociais e dos cidadãos de valores positivos em valores negativos, na medida em que, segundo aquele argumento, as lutas e conquistas significam excesso de demandas e comprometeriam o equilíbrio do sistema" (Ivo, 2001B, 80). Así mismo, mercantiliza los derechos y conquistas de los/as trabajadores, convirtiéndolos en bienes y servicios a ser adquiridos en el mercado, al margen del Estado.

Es decir, el Estado abandona su lugar de coordinador y garante de los derechos sociales y económicos, a favor del Mercado. De esta manera son los individuos en competencia, las propias familias, que deben resolver su supervivencia de manera privada. Todo lo cual se traduce en un traspaso de las responsabilidades del Estado a la Sociedad, particularmente, a los sectores populares y sobre todo sobre a las mujeres, quienes asumen la responsabilidad de asegurar la subsistencia de sus familias, a través del trabajo doméstico remunerado y el trabajo comunitario.

\section{La Argentina Neoliberal y Los Sectores Populares}

"Lo más notable de esto es que todos los afectados, el conjunto de la sociedad, consideran y tratan a la crisis como algo fuera de la esfera de la voluntad 
y el control humanos, un golpe fuerte propinado por un poder invisible y mayor, una prueba enviada desde el cielo, parecida a una gran tormenta eléctrica, un terremoto, una inundación..."

Rosa Luxemburgo

La Argentina del Neoliberalismo se comienza a perfilar en las políticas llevadas a cabo por la última dictadura militar (1976-1983). Es a partir de allí, cuando la ciudadanía entró en un tobogán de pérdida de derechos y de soberanía, que paradójicamente, continuó con el advenimiento de la Democracia en 1983. La era del libre mercado llegó para quedarse hasta comienzos del siglo XXI.

La presidencia de Carlos Menem (1989-1999) es el icono de la era neoliberal en este país, por la profundidad de las medidas económicas y el desembarco de las empresas transnacionales y los capitales financieros. Es en esta época que se impuso la disminución del tamaño del Estado por reducción de gastos fiscales. Los ajustes estructurales se tradujeron en la más profunda distribución regresiva de los ingresos ciudadanos y la pobreza creció exorbitantemente. Problemas estos que fueron construidos, desde el Estado, como residuos que debían ser paliados con medidas asistencialistas. Esto implicaría la "clasificación" de los pobres, es decir, ordenarlos para posibilitar la focalización de las políticas, reemplazando buena parte del gasto en las políticas de carácter universal:

En nombre de la racionalidad del gasto en el Estado, se restringieron sistemáticamente las inversiones y el financiamiento de servicios públicos fundamentales como la salud, la seguridad e infraestructura pública, la educación y la investigación científica (Grassi y Alayon, 2004, 4).

En este marco de regresividad del gasto público, las políticas ofrecieron asistencia para la alimentación -a través subsidios a comedores, programas de reparto de alimentos, bonos o tickets-, ayudas económicas para microemprendimientos productivos y capacitación para el primer empleo y la formación o reconversión profesional, etc.

Las protagonistas, en tanto destinatarias de estas políticas y programas sociales diseñados desde una perspectiva gerencial, por lo 
general, fueron las mujeres de sectores populares. Dado que dichos programas requerían trabajo comunitario y, consecuentemente, exigían una constante participación femenina. Barrancos describe que: "miles de mujeres trabajaron a destajo para desarrollar programas asistenciales y se envolvieron directamente en la gerencia de emprendimientos para mejorar a sus familias y a sus comunidades" $(2007,42)$. Lo que implicó que las mujeres pagaran de hecho el costo del ajuste, al sustituir con su trabajo social y familiar aquellas funciones que el Estado, en sus diferentes niveles, dejaba de atender. Así, con la intensificación del trabajo doméstico y de las tareas del cuidado ampliadas en ocasión de las privatizaciones y el recorte en gasto, funcionaron como un factor oculto de equilibrio que absorbió los shocks sociales que acarreaban el ajuste y, posteriormente, la crisis ${ }^{3}$.

También a principios de los noventa se produce un cambio en los modos de la acción colectiva. La crisis de las organizaciones tradicionales de la sociedad (partidos y sindicatos), la descolectivización "sin precedentes", propia del predominio de una ideología individualista consagrada en el "sálvese quien pueda"; tiene su contrapunto en la movilización de los sectores populares, que emergen como los principales sujetos de la acción política-social que da cuenta de la crisis del modelo de organización (cfr. Svampa y Pereyra, 2003).

La organización comunitaria o territorial, las llamadas "puebladas", empieza a ser el modo privilegiado en que dichos sectores se organizan y articulan con otros actores externos como ONG u movimiento sociales. Como afirman Svampa y Pereyra, “En la medida en que se agraven las condiciones de vida de las clases populares y se acentúe la distancia con el mundo de trabajo formal, la militancia territorial va a revestirse de nuevas dimensiones" (2003, 39). Los barrios se vuelven el escenario de organización y de las luchas reivindicativas y de resistencia: se organizan los "Piqueteros"4 (1996-97) y emergen también las "ollas populares", en el marco de organizaciones que, si bien ya existían antes, comienzan a adquirir fuerza y se constituyen en centros desde donde reclamar al Estado por la crisis, tales como las sociedades de fomento, los centros vecinales, cooperativas, comunidades eclesiales, ONG, etc. Es lo que Modonesi (2008) denomina: "politización de abajo", un proceso de subjetivación antagonista al modelo hegemónico, que genera organización política sobre las bases o desde una forma comunitaria. 
No obstante, hacia el final de la década de noventa, se destacaba el sometimiento de la política a la economía, no solo por parte del Estado sino también de los sindicatos ${ }^{5}$ y muchas otras organizaciones que resignaban sus intereses de clase a cuestiones corporativas e incluso personales, mientras las clases medias se encontraban obnubiladas por el acceso al consumo y la ficción de la convertibilidad (un dólar igual un peso).

Pero las consecuencias sociales de la implementación de este modelo eran devastadoras: desempleo estructural, fragmentación social, las sociedades se polarizan entre pobres y ricos, llevando a una importante parte de la sociedad a sobrevivir con la asistencia estatal, muchas veces teñida de clientelismo y abuso político. En este proceso, como vimos, los más golpeados son los sectores desempleados y sobre todo las mujeres y los/as jóvenes, cuyos índices de informalidad y desempleo son más altos que los de cualquier otro grupo ${ }^{6}$.

\section{La Crisis y las mujeres}

"Quien no se mueve no siente las cadenas" Rosa de Luxemburgo

Ante el ajuste y la crisis social, las demandas por trabajo, asistencia social y ayuda alimentaria confluían en el reclamo de las mujeres que se posicionaron, en muchos casos, como madres en representación de sus familias. Según Svampa, la figura de la madre emergió como la portadora de una interpelación radical que rompió con las clásicas visiones entre el espacio privado y el público:

En realidad las mujeres decidieron dejar el ámbito doméstico y barrial y salieron a cortar la ruta en muchos casos sin el acuerdo de los maridos, como último recurso, esto es, cuando la realidad desnuda del desempleo se cruzó sin más con la experiencia límite del hambre $(2007,163)$.

En este sentido, Dora Barrancos explica que la desocupación, que golpeó a las jefaturas de familia masculinas, obligó a las mujeres a salir del hogar y buscar empleo:

Fueron especialmente los hogares más pobres los que vivieron esta experiencia expansiva de las mujeres como principal soste- 
nedoras, puesto que en el segmento menos favorecido se pasó del 18,5\%, a inicios de la década, al 27,5\% hacia 1997 (2007, 305).

Es en esta época que se expande la feminización de la pobreza, en parte, debido al impacto del desempleo en los hogares monoparentales de jefatura femenina. Este proceso, se evidencia en 1999, cuando las mujeres pobres alcanzan tasas de desocupación un $160 \%$ superior al resto de las mujeres. A partir de lo cual Benito concluye que:

(...) ser mujer y pertenecer a hogares en situación de pobreza es colocarse en el nivel más bajo de acceso al mercado laboral y ya dentro de éste ubicarse en los lugares de mayor desigualdad e inequidad laboral. En este caso el sector social y el género producen una infeliz combinatoria que ubica a estas mujeres en el lugar más desigual de toda la escala social y laboral $(2000,34)$.

Así, las mujeres de sectores populares en la década neoliberal, con un claro déficit en el ejercicio de sus derechos derivado de la pronunciada inequidad social, se convirtieron en el blanco de la política asistencialista, que las focalizaba de manera reduccionista como protagonistas de la búsqueda del sustento familiar y la reproducción cotidiana de su existencia y les condicionaba el desarrollo de la conciencia colectiva o autonomía ${ }^{7}$.

Sin embargo, al salir al espacio público las mujeres de sectores populares estaban desafiando la dinámica y roles familiares, cobrando relevancia social y aprendiendo a reclamar por sus derechos. Como afirmáramos arriba, en este período habían ganado una fuerza especial los movimientos y organizaciones barriales y comunitarios en los cuales, en principio, las mujeres jugaron un papel fundamental a través de la gestión de recursos, la organización de la producción y el consumo cotidiano (en guarderías, comedores, roperos comunitarios, etc.), dirigidos a cubrir las necesidades básicas de sus familias ${ }^{8}$. Svampa y Pereyra (2007), dirán entonces que en estas organizaciones continúa primando el rol tradicional de la mujer que se organiza por el cuidado de los otros/as.

Sin embargo, después de un estudio de largo plazo, Di Marco propone distinguir las mujeres "en movimiento" de las mujeres que participan de "procesos democratizadores" (asambleístas, pique- 
teras y obreras de fábricas recuperadas), atribuyendo a las segundas la potencialidad para el desarrollo de intereses estratégicos de género en función de las condiciones y modalidades de la acción colectiva que favorecerían en estas últimas el desarrollo de "prácticas más autónomas" $(2011,302)$. Siguiendo a Molyneux, tendrían la capacidad de superar las necesidades y demandas prácticas, que las mantienen en posiciones subalternas vinculadas a la reproducción y al mencionado rol materno, para desarrollar intereses y demandas estratégicas de género, derivados de la conciencia de su situación de subordinación.

Las mujeres "en movimiento", definidas como "aquellas que actúan conjuntamente para alcanzar objetivos comunes, sean o no feministas" (Di Marco, 2011, 302), en cambio, constituirían un primer paso para romper las barreras de lo privado. Aunque la autora deja ver cierto pesimismo cuando se trata de atribuir la prácticas organizativas de estas mujeres el carácter de "camino sin retorno" para la transformación, para que desarrollen su propia voz, sus intereses. Esto en orden al conjunto de recursos, herramientas de que dispondrían para significar su posición y así definir otros horizontes de posibilidad para sus prácticas e intereses.

No obstante, el caso de referencia para este trabajo nos mostrará que aún en estos casos, donde la mujer no sólo salió a trabajar, sino que también se ocupó de discutir y formar parte de espacios colectivos comunitarios de acción y reivindicación pública, es posible observar que la participación femenina, repercute en la familia y en su organización, así como en los roles públicos asignados tradicionalmente desde el género, que pasaron a ser tensionados y hasta cuestionados por las propias mujeres en la práctica.

\section{Relatos de experiencias femeninas situadas}

"Lo que determina la vida del ser humano/a

Es en gran medida el peso de las palabras o el peso de su ausencia.

Cuanto más capaz es unola de nombrar lo que vive, Más apto/a será para vivirlo y transformarlo"

Michele Petit

Es en el mencionado contexto argentino, de pobrezas y exclusión para las mujeres, donde paradójicamente se sancionaron legis- 
laciones y se ratificaron los compromisos asumidos en conferencias internacionales favorables para las mujeres (como la ley de cupo femenino, el divorcio vincular, la Conferencia Internacional sobre la Población y el Desarrollo, la Cuarta Conferencia Mundial sobre la Mujer). Además, en un contexto donde existían retrocesos en el ejercicio efectivo de los derechos ciudadanos, las mujeres conquistaban espacios en el mundo público comunitario, ocupando posiciones de liderazgo social, de coordinación y de visibilidad pública. Entre esos movimientos de ocupación del espacio público y de visibilización de las mujeres como sujetos de derecho, es que recuperamos las experiencias de participación comunitaria, impulsadas por las mujeres de la ciudad de Rosario, Argentina.

En primer lugar, resulta difícil describir el estado de situación que se vivía en dicha ciudad en el contexto neoliberal, dado que los datos que se trabajan y producen en Argentina, pertenecen al Gran Buenos Aires y a los restantes aglomerados urbanos 9 . A modo de caracterización podemos señalar que, para el Censo 2001, Rosario tuvo el alza de desempleo más importante de la Argentina (la tasa de desempleo se incrementó 5 puntos porcentuales). Del total de hogares de Rosario, el 11, 8\% eran hogares con necesidades básicas insatisfechas y de ese total el $26,67 \%$ tenía una mujer como jefe de hogar. La posición de las mujeres en el mercado de trabajo rosarino, se encontraba concentrada en algunas ramas de actividad identificadas con ocupaciones catalogadas como "femeninas". Principalmente, vinculadas a las tareas reproductivas (en el área de educación, en servicios de salud, en servicios personales y en el propio empleo doméstico).

En segundo lugar, en el marco de los programas de ajuste estructural, las organizaciones y espacios de encuentro de las mujeres de sectores populares se convirtieron en alternativas para la supervivencia y participación. Sin embargo, las demandas que las movilizaron no tuvieron que ver con reivindicaciones propiamente de género, sino con la lucha por garantizar la supervivencia de los miembros del hogar, el bienestar familiar, la ayuda a los otros/as y la satisfacción de las necesidades de la familia (acceso a la salud, alumbrado en el barrio, etc.) Estos motivos primaban y priman en las experiencias actuales para organizarse ${ }^{10}$, por lo que la participación en primera instancia pareciera ser una extensión de las tareas domésticas y del cuidado maternal: 
“... [empecé a participar...] en 2001...cuando tuve que ir a un trueque para sobrevivir... Yo tengo una hermana que pasaba hambre y me decía: 'vas a un trueque? Vos estás loca!' y ¿por qué no? Mis hijos no pasan hambre..." (Entrevista a Gloria, 2011).

"Yo empecé en el 2001... [...] Y bueno, a mí siempre como que me llamó la atención el sentimiento mío de ayudar a los demás... Y bueno, empecé a ir... primero empecé a ir con un grupo, era una ONG, creo..." (Entrevista a Mabel, 2011).

No obstante, las organizaciones y las formas en que las mujeres participaban eran diversas, pero se privilegiaba la opción por la acción colectiva, unirse con otras que comparten las mismas condiciones de existencia, para hacerle frente a la desocupación y a otros problemas derivados de las múltiples manifestaciones de la situación de pobreza. Las estrategias dan cuenta, entonces, de entretejidos y articulaciones complejas de mujeres que, como referentes de diferentes actividades y sectores en el territorio, permiten construir una malla que viabiliza y garantiza los emprendimientos, además de integrar nuevas mujeres al espacio público: "Y como que con Mabel hicimos más vínculos y... así que cuando había reuniones de otras cosas también la acompañaba y me fui involucrando en otras cosas..." (Entrevista Vanesa, 2011).

Es allí donde se ponen en juego y socializan distintos saberes y recursos disponibles en la comunidad para el diseño de soluciones y el acceso colectivo a recursos básicos:

“... yo tenía una máquina de coser... empezamos a hacer cosas... tres o cuatro mujeres que éramos... y cocíamos y lo que hacíamos lo vendíamos y comprábamos la leche, el harina para hacer el pan. [...] Y bueno, nos daban las semillas y nosotros acá atrás teníamos la huerta. Entonces, lo que sacábamos de la huerta vendíamos en el trueque [...] En el trueque comprábamos la leche... con las otras cosas comprábamos la harina, la levadura... y bueno, empezamos a hacer la copa de leche. Le dábamos una copa de leche, dos veces por semana, a 50 chicos" (Entrevista a Mabel, 2011).

Así, las mujeres movilizaron recursos y generaron acciones en los barrios para dar respuestas a necesidades urgentes de sus comunidades. También avanzaron en la gestión de recursos públicos y de fondos provenientes de la ayuda internacional, canalizada a través 
de diversas organizaciones no gubernamentales para financiar los emprendimientos comunitarios autónomos:

“Nos sustentamos con el PNUD. Así que tuvimos la suerte de encontrar un programa que realmente nos sustenta muy bien en los alimentos que nos dan, ¿no? Y bueno, pero anteriormente, peleamos mucho y tuvimos que hacer mucho, porque nosotros lo teníamos ya a un año, ya funcionando como una copa de leche... lo hacíamos por cuenta nuestra" (Entrevista Mabel, año 2011, sic).

Si bien los relatos destacan que las organizaciones de base, como comedores, copas de leche o clubes barriales, eran lideradas mayoritariamente por mujeres, durante el período de crisis las cuestiones de género no eran específicamente abordadas, sino que la tarea se centraba en la organización colectiva por la supervivencia:

“Eran todas mujeres... el único varón era mi esposo que nos apoya... [¿hablaron de cuestiones de género o de mujeres en esos grupos?] No, nunca hablamos... porque incluso yo misma tenía... mucho tiempo tuve problema de... familiares, digamos. Y era como que todo tenía un límite" (Entrevista Mabel, 2011).

Con el tiempo la supervivencia no es el único motivo de participación que destacan las mujeres, sino que hablan de diversas intenciones y/o motivaciones para salir al espacio público, sobre todo el hecho de vislumbrar la posibilidad de modificar la realidad, personal y colectiva, para hacerla más justa:

“...nosotros gente común no vamos a sacar los chicos de la calle ni vamos a cambiar el mundo, pero por ahí, si todos participáramos -en un club, en un comedor como hace Mabel o con un grupo de chicos- si nos involucramos sería todo más distinto. [...] A mí me gustaría si vería que la gente cambie la forma de pensar, pero sé que no se puede... por ahí, vos ves que hay un cambio..." (Entrevista Gloria, 2011, sic).

"Y me pareció lindo [participar] porque como que te ayuda a sentirte útil, que haces algo para tu familia, para vos y para otros, porque desde allá no sólo estás para tus hijos sino para muchos chicos más, que las mamás también van al comedor. [...] Y desde allí es como que volví a revivir un poco." (Entrevista Vanesa, año 2011, sic). 
El encuentro con otras mujeres, otras formas de socialización también forman parte de las motivaciones que impulsan a las mujeres en la búsqueda de espacios colectivos, destinados a la lucha por el barrio y sus espacios públicos, la acogida de mujeres víctimas de la violencia de género e inclusive oportunidades de capacitación para superar la situación de desempleo. Los datos provenientes de las fichas de inscripción a los cursos para capacitación en oficios no tradicionales, ofrecidos por la Municipalidad de Rosario, dan cuenta de estas motivaciones. En una pregunta de opciones múltiples, donde las aspirantes podían escoger más de una alternativa, la motivación más elegida fue "conocer personas y generar vínculos (63\%) y sólo en segundo plano se encuentra la opción por "crear un emprendimiento económico" (44\%), seguidas de "inserción laboral" (37\%) y "mejorar ingresos" y "realizar tareas extradomésticas" (27\%). Como afirmaba la Directora del Área Mujer del municipio: “...una motivación que las involucra mucho es conocer otra gente, tener otros espacios de relacionamiento." (Entrevista a Alonso, Cit. en Echavarría, 2007).

En estos espacios, superada la situación de crisis, tienen la oportunidad de conocer sus derechos y reconocer sus capacidades, abriendo nuevas oportunidades para cuestionar su posición, tanto en la familia como en la comunidad:

"Por ahí me desilusiona mucho con mi marido también... como si él, ahora con el tiempo yo me doy cuenta que él me quiere ahí [en casa]. Yo calculo que fue por celos siempre. Muchas veces que voy a una charla y que vuelvo... [digo] ahora me doy cuenta de muchas cosas... Uh! No sabés lo que me dice! "Me parece que vos no vas a ir más, porque ahí te están lavando la cabeza" Claro, porque yo era como si estaba en un caparazón [...] yo ahora que voy a todos estos grupos, yo veo que me tenía que aguantar y viste por ahí y me lo aguantaba... yo por ahí, yo hubiera estado en otro grupo decía: ¿por qué?, ¿qué problemas tenés?, ¿vos no te sentís seguro?" (Entrevista Gloria, 2011, sic)

Como vemos en este testimonio, en esos grupos, las mujeres comienzan a reflexionar sobre las relaciones de género y sobre las violencias que ejercen sus parejas varones. Por eso, estos espacios pueden ser puentes de reflexión, de organización y muestran como los intereses por la reproducción se encuentran entrelazados con las 
necesidades estratégicas de género.

\section{El estallido de la participación femenina...}

“(...) Mis silencios no me han protegido. Vuestros silencios no os protegerán. Pero con cada palabra real que he pronunciado, Con cada intento realizado de decir verdades

Que aun ando buscando, He entablado contacto con otras mujeres

Que buscan conmigo esas palabras Que puedas encajar en el mundo En que todas creemos" Audre Lorde

Para muchos/as autores que tomamos como insumo para este ensayo, los grupos como los que mencionamos, las luchas de estas mujeres sostienen, suelen ser consideradas parte de las conductas esperadas por el orden patriarcal establecido. La participación comunitaria y organizativa de los sectores populares de la década neoliberal, es descripta como un rol que es asumido por las mujeres en términos de lo normal y naturalizado según el rol o papel de género. Frente a estas presunciones nos preguntamos, ¿esta participación comunitaria de la mujer sigue sujetándola a roles tradicionales de género o puede ser parte de un proceso emancipador?, ¿Será la participación comunitaria la forma distintiva que adquiere la participación política para las mujeres de sectores populares? Que la participación comunitaria de las mujeres de sectores populares tenga un estallido en el contexto de los 90 en Argentina, ¿significa que las mujeres solo se organizan cuando la crisis asfixia su economía?, ¿podemos considerar estas manifestaciones de base como participación política? A partir de lo trabajado podemos arriesgar algunas respuestas provisorias.

Considerando que la participación política, tanto en el ámbito público social como en el formal o estatal, se encuentra condicionada por la situación histórica y la posición del/a sujeto (hablamos de clase y género), es posible afirmar que en contextos de extrema pobreza, las mujeres encuentran que participar en relación a la supervivencia, a la solución de las denominadas necesidades prácticas adquiere prioridad frente a la problematización de las cuestiones de 
género. Esto podría asociarse a un análisis costo-beneficio que no las pone en el centro de la maximización, pero también con lecturas de escenario, con sentido práctico propio de su cultura política. Según el cual, pareciera que participar en su comunidad, junto a sus vecinos/as, en el barrio y por necesidades básicas, permite abordar las necesidades, vida privada familiar y al tiempo que dar cuenta del escenario público del ejercicio de la política como compromiso con lo colectivo, con lo que es común a todos/as. En tal sentido, podría afirmarse que la movilización de las mujeres en torno de las denominadas necesidades prácticas forma parte de un proceso que tiene la potencialidad de subvertir el enclaustramiento doméstico o privado de las preocupaciones y/o atenciones de las mismas.

Además, el participar en cuestiones que se relacionan con necesidades familiares parece haber facilitado a las mujeres una salida legitima del espacio doméstico al espacio público, evitando conflictos intrafamiliares basados en las asignaciones tradicionales de roles. Esto tiene la potencialidad de que las mujeres se relacionen con otros/as y, efectivamente, participen inclusive cuestionen los mandatos de género que las circunscriben a lo doméstico y al cuidado de los otros y ocupen de manera protagónica el espacio público. Nuevamente, si la "salida" se da en el marco del orden de dominación y legitimación patriarcal, no podemos dejar de señalar que el hecho constituye una condición de posibilidad para el desarrollo de la subjetividad política de las mujeres.

El contenido político de las acciones públicas que las mujeres desarrollan, desde su condición de madres, hijas y hermanas a cargo de la atención y/o cuidado de otros/as, reside también en los sentidos atribuidos por las mujeres a los espacios de organización comunitaria. Los mismos son descriptos desde una perspectiva intertemporal -tal y como sucede en las mujeres de movimientos sociales consideradas por Dimarco- como espacios de acción colectiva para la organización y reivindicación de derechos de los/as otros/as, pero también, fundamentalmente, de los propios. En la acción política-comunitaria sostenida en el tiempo más allá del momento de crisis, las mujeres ponen de manifiesto que lo privado es público, rompiendo con las esferas de lo público como solo masculino y lo femenino como lo privado y demostrando, así mismo, que lo que se entiende como femenino no es propio sólo de las mujeres sino de una posici- 
ón: la subalterna.

Amplían de esta manera el abanico de cuestiones que pueden ser problematizadas en el ámbito público y, en tal sentido, consideradas contenido legítimo de la acción política. Cuestiones estas que suceden al interior de la esfera privada pero que tienen que ver con el efectivo ejercicio de los derechos ciudadanos/as (comer, abrigarse, recrearse, tener vivienda, educación, no ser sujeto de violencias, etc.) en un contexto claramente deficitario.

A modo de síntesis, podemos afirmar que las mujeres de sectores populares, que encuentran un pico de participación a fin de los años noventa, hacían y hacen política; ejercían entonces y ejercen hoy el poder, en tanto capacidad de encontrar nuevas formas de viabilizar respuestas con vistas a una vida cualitativamente mejor, como posibilidad de transformación de sus vidas cotidianas. Al decir de Virgina Guzmán: “(...) tal que problemas antes vividos en la esfera privada y como destino personal eran politizados, dando lugar a procesos de construcción de autoestima personal, social y genérica" (2011, 45). En tal sentido, consideramos que no debemos reflexionar sobre sus experiencias históricas de manera dicotómica, esto es, separando artificialmente lo privado de lo público, lo personal de lo político.

Entonces, si entendemos que la participación política es, como plantea Lechner (1988), un ritual, una identidad colectiva en permanente construcción, es posible pensar, a partir de lo dicho, que la participación comunitaria de las mujeres de sectores populares, manifestada en la búsqueda de solución a múltiples necesidades familiares, tiene en su ejercicio una dimensión política siempre presente. Además, las acciones y estrategias comunitarias, los grupos de base, los movimientos populares de referencia de estas mujeres en el contexto neoliberal, no constituyen meras salidas basadas en la simple agregación de las experiencias individuales sino que fueron y son expresión de genuinos procesos de organización, que impactan, influencian y generan vida social, así como marcan sus trayectorias individuales. Todo esto, independiente del hecho de que, parafraseando a la autora antes citada, tengan más o menos conciencia de su potencial, intención o no de superar o avanzar en la transformación de su posición de doble subordinación social y de reconocerse desde el inicio como parte del colectivo MUJERES. 


\section{Notas}

1. Las mujeres entrevistadas pertenecen al Distrito Noroeste [DNO] de la ciudad de Rosario, una de las dos áreas de intervención seleccionadas por el Programa Gender Inclusive Cities, implementado por CISCSA - Red Mujer y Hábitat-, coordinado por Women in Cities International y financiado por el UN Trust Fund. El mismo buscaba incrementar la seguridad de las mujeres promoviendo la equidad en el acceso de las mujeres a los espacios públicos.

Los testimonios son de mujeres del Distrito Noroeste de la ciudad; el cual tiene una población de 155.850 habitantes, el 17,13\% del total de la ciudad, y entre otros factores actualmente registra con un alto porcentaje de Necesidades Básicas Insatisfechas (entre el 15\% y el 26\%) (Cfr. Blanes y Perez, 2011).

2. Para esta época, las cifras hablan de una Latinoamérica que contaba con un $48.3 \%$ de pobreza, de la cual un 22.5 era indigencia. Para 1996, según indicadores del Informe Argentino sobre desarrollo humano, el 10\% de la población más rica se apropiaba del $37 \%$ de lo producido, mientras que el $50 \%$ más pobre recibía el $19 \%$. Un $26.7 \%$ de la población urbana argentina vivía bajo la línea de la pobreza, y en el Conurbano Bonaerense un 40\%. Ya en 1999, el 10\% más rico obtenía casi la mitad del ingreso nacional, un $48.3 \%$, mientras los más pobres tan solo un $1.3 \%$ del ingreso total. Es decir que el décimo más rico del país ganaba cuarenta veces más que el décimo más pobre

3. Los estudios indican que existe una estrecha relación entre periodos de ajuste y ampliación del trabajo femenino, dado que la mujer ajusta su comportamiento y amplía su trabajo para mantener el nivel de consumo de su familia. (cfr. Girón, 2007)

4. Movimiento social cuya identidad en común está definida por la "desocupación", sus repertorios de acción incorporan los cortes de ruta y quemas de goma, que denominan "piquete". Demandan al Estado por el cumplimiento de su función de garante de los derechos sociales y económicos, concretamente, asistencia social e inclusión a través de "trabajo digno". (Cfr. Svampa y Pereyra, 2003)

5. Sin bien, para entender la particular situación del sindicalismo y del movimiento obrero, no debemos dejar de tener en cuenta que durante la dictadura militar, se produjo la "desaparición forzada" de trabajadores, la prohibición de los sindicatos y la eliminación del derecho de huelga. A lo que se suma el conjunto de reformas laborales impulsadas ya en la etapa democrática, que promovieron una relación de nuevo tipo entre el capital y el trabajo, por lo que el panorama parecía no ser muy alentador para organizarse.

6. En el 2001, según la ONG Comparte, el 30\% de la población se repartía más de la mitad de la riqueza del país, un millón y medio de personas soñaba con irse de la Argentina y el 70\% de los/as niños/as y adolescentes sufría pobrezas. Reforzando estos datos, según la encuesta permanente de hogares de 2001, casi 5 millones y medio de personas vivían con menos de 1 dólar por día, mientras el 10\% más rico lo hacía con 95 dólares diarios. En octubre de 2002, el 57,5\% por ciento se encontraba en situación de pobreza, lo que incluía a unos 7 millones de mujeres, cuya distribución verifica al interior de la misma, el nivel más alto de indigencia en el tramo de las edades de 0-14 años (casi 1,335 millones de niñas).

7. Quiroga refiere al "déficit de ciudadanía" al analizar el ejercicio efectivo de dere- 
chos en la Argentina de la crisis neoliberal, basado tanto en las condiciones materiales del ejercicio como en la idea de "conciencia de derechos" -tomada de Lefort. (Cfr. Quiroga, 2006)

8. Entre los modos de organización territorial, que reclamaban ante la pobreza y la exclusión, el movimiento piquetero logra que su demanda sea canalizada en 1995 por el Estado a través del otorgamiento de los "Planes Trabajar", financiados por el BM y el BID, programas de transferencias condicionadas que demandaban contraprestaciones de los destinatarios en la forma de servicios a la comunidad, como atención de niños y ancianos, comedores, roperos comunitarios, etc.

9. Datos construidos para las principales ciudades y sus áreas metropolitanas, además agrupados por regiones.

10. Cfr. Bard Wigdor G. Experiencias que se encuentran en el programa primeros años: Participación comunitaria de mujeres de sectores populares. En: II Congreso Interdisciplinario en Género y Sociedad. "Lo personal es Político". Universidad Nacional de Córdoba, 2012.

\section{Bibliografía}

Banco Mundial. Informe Anual 1990. Washington, 1990.

Barrancos, Dora. Mujeres en la Sociedad Argentina. Una historia de cinco siglos. Buenos Aires: Sudamericana, 2007

Benito, María. "La explosión de la pobreza en la Argentina. Indicadores de un crecimiento alarmante". En: CELS. Derechos Humanos en Argentina. Informe Anual 2000. Disponible en: http://www.cels.org.ar/common/documentos/ informe_2000_cap_3.pdf

Blanes, Paola y Soledad Pérez. “Ni solas ni silenciadas, en la calle libres y desatadas: construyendo una ciudad sin violencia y más segura para todas y todos. La experiencia organizativa de las mujeres en tres distritos de la ciudad de Rosario, Argentina". En: Blanes et al. Construyendo Ciudades Seguras: Experiencias de redes de Mujeres de América Latina. Chile: Red Mujer y Hábitat de América Latina, 2011.

Borón, Atilio. "A sociedade civil depois do dilúvio neoliberal". Pós-neoliberalismo: as políticas sociais e o Estado democrático. 4 ed. Rio de Janeiro: Paz e Terra, 1998.

Draibe, Sonia y Enrique Wilnês. “Welfare State, crise e gestão da crise: um balanço da literatura internacional". Revista Brasileira de Ciências Sociais, São Paulo, v. 3, n. 6, p. 53-78, fev. 1988.

Echavarría, Corina. "De la eficiencia a la legitimidad: contextos y actores de la participación en Argentina". II Seminario de la Red de Análisis de Prácticas Participativas en América Latina y Europa. Jalapa, México, 2011 (mimeo) -. "Espaço público e institucionalização: resistências à organização formal do Plan Estratégico de la Ciudad de Córdoba (Argentina) e do Orçamento Participativo de Porto Alegre (Brasil)". Tesis Doctorado en Administración. Núcleo de Pós-Graduação em Administração, Escola de Administração Universidade Federal da Bahia, 2005.

Echavarría, Corina. “Género y presupuestación participativa: Autonomía de las mujeres y presupuesto participativo en la ciudad de Rosario, Argentina". 
Diplomado Superior en Presupuesto Público pro-Equidad de Género contra la pobreza en América Latina y el Caribe. Flacso, 2007.

Giron, Alicia. (Ed.), Género y Globalización, Argentina: editorial CLACSO, 2009.

Grassi Estela y Norberto Alayon. "El ciclo neoliberal en la Argentina. La asistencialización de la política social y las condiciones para el desarrollo del trabajo social". Diciembre, año 2004. Disponible en: www.iigg.fsoc. uba.ar/grassi/archivos/CicloNeolib.doc

Guzman, Virginia. Conversaciones a través del Tiempo y a la distancia, Chile: Centro de Estudios de la Mujer, 2011.

Harding, Sandra. Ciencia y feminismo, Madrid: Morata, pp. 15-27.1996.

Ivo, Anete Brito Leal. "A destituição do "social": Estado, governo e políticas sociais". Caderno CRH, Salvador, n. 35, p. 41-84, 2001.

. "As transformações do Estado Contemporâneo". Caderno CRH, Salvador, n. 35, 11-20, 2001.

Kaufman, Robert. "A política da reforma do Estado: um exame de abordagens teóricas". Revista do Serviço Público, Brasilia, ano 49, n.1, . p. 43-69, 1998.

Koldorf Ana Esther. Familia y nueva pobreza desde una perspectiva de género, Rosario 1994-2002, Argentina: editorial Prohistoria, 2008.

Lechner, Norbert. Los patios interiores de la democracia. Subjetividad y Politica. Santiago de Chile: FLASO, 1998.

Modonesi, Massimo. “Crisis hegemónica y movimientos antagonistas en América Latina. Una lectura gramsciana del cambio". Contra Corriente, Vol.5, №2, PP. 115-140. Universidad Autónoma de la Ciudad de México y Universidad Nacional Autónoma de México, 2008.

Naceti Beatriz y Terrero Magdalena, ¿Por qué lo privado se hace público?: Investigación de sectores populares urbanos y rurales desde un enfoque de Género, Argentina: Editorial Espacio, 1997.

Quiroga, Hugo. “Déficit de ciudadanía y transformaciones del espacio público", en: Cheresky, Isidoro. Comp. Ciudadanía, sociedad civil y participación política, Argentina: Miño y Dávila, 2006. Pp 109-140.

Schmidt, Benício Viero. "O Estado, a nova esquerda e o neocorporativismo". Caderno CRH, Salvador, n. 35, p. 85-105, 2001.

Svampa, Maristella (Ed.) Desde Abajo: las transformaciones de las identidades sociales. Universidad Nacional de General Sarmiento: Editorial BIBLOS, 2007.

Svampa M. Y Pereyras. Entre la Ruta y el Barrio: las experiencias de las organizaciones piqueteras. Argentina: editorial BIBLOS, 2003.

Tenti Fanfani Emilio. "Notas sobre la exclusión social y acción colectiva. Reflexiones desde Argentina. La Política Social desde la Constitución de 1991 ¿una década perdida?, Facultad de Ciencias Humanas: colección Ces, 2004.

Vargas Valiente, Virginia. Ed. Patricia Portocarrero Suárez. “Los intereses de las mujeres y los procesos de emancipación". Estrategias de desarrollo: intentando cambiar la vida. Lima: Flora Tristán ediciones, 1993.

Varone Víctor. "Globalización y Neoliberalismo. Elementos de una crítica". Documento de trabajo № 95, Argentina: CLACSO, 1998. 